\title{
Nuevas fórmulas para la televisión en directo: el uso de Facebook Live en Atresmedia
}

\author{
Dra. Mercedes Herrero de la Fuente | mherrero@nebrija.es \\ Universidad de Nebrija
}

\author{
Palabras clave \\ audiencia social; engagement; Facebook Live; live \\ streaming; periodismo transmedia; MoJo. \\ Sumario \\ 1. Introducción. 2. Objetivos. 3. Marco teórico. 4. \\ Metodología. 5. Análisis de los resultados. 6. \\ Conclusiones. 7. Bibliografía. 8. Notas
}

\section{Resumen}

Las televisiones utilizan las redes sociales para captar audiencias y, a medida que el ámbito del Social Media incorpora novedades, estas son adoptadas para conseguir el ansiado objetivo del engagement. El último estadio en esta rápida evolución es la utilización del live streaming, que permite una conexión en directo a través de un dispositivo móvil. Pocos meses después de lanzarse Facebook Live, Atresmedia lo incorpora a sus diversos perfiles en Facebook, especialmente al de los informativos y al genérico de la cadena. Este trabajo se centra en analizar cómo se usan estos live en ambas cuentas a los largo de marzo de 2017, con el fin de determinar temas, pautas narrativas, lenguaje audiovisual y, en última instancia, si existe una estrategia clara en la adopción del live streaming mediante Facebook. Los resultados de esta investigación revelan unos criterios bastante definidos, sobre todo en los Facebook Live de la cuenta Antena 3, centrados fundamentalmente en la promoción de determinados programas de entretenimiento (incluyendo lo relacionado con la Champions League). El potencial de estas conexiones para la información de actualidad está menos aprovechado, pero cuando se llevan a cabo consiguen también un gran eco en Facebook.

\section{Cómo citar este texto:}

Mercedes Herrero de la Fuente (2017): "Nuevas fórmulas para la televisión en directo: el uso de Facebook Live en Atresmedia”, en Miguel Hernández Communication Journal, n8, pp. 521 a 563. Universidad Miguel Hernández, UMH (Elche-Alicante). Recuperado el de de 20__ de: [ink del artículo en mhjournal.org] 


\title{
New formulas for live television: the use of Facebook Live in Atresmedia
}

\author{
Dra. Mercedes Herrero de la Fuente | mherrero@nebrija.es \\ Universidad de Nebrija
}

\section{Keywords}

engagement; Facebook Live; live streaming; MoJo; social audience; transmedia journalism. Summary

1. Introduction. 2. Objectives. 3. Theoretical framework. 4. Methodology 5. Results analysis. 6. Conclusions. 7. Bibliography. 8. Notes

\section{Abstract}

Social media is used by TV channels to obtain higher ratings and as social media changes and evolves, its innovations are adapted to reach the prized engagement. The latest tendency in this fast evolution is live streaming, which allows a live connection through a simple mobile phone. Just a few months after launching Facebook Live, Atresmedia incorporated it into its different Facebook profiles, especially in the news and in the general profile of the channel. This paper aims, on the one hand, to analyze how live streaming was used in both Facebook accounts during the month of March 2017 and, on the other hand, to determine topics, narrative guidelines, audiovisual language and, as a last resort, if Antena 3 TV has a clear live streaming strategy on Facebook. The results of this research show very well defined criteria, especially on the Antena 3 Facebook account. These criteria are fundamentally centered on the promotion of specific entertainment programs, (including those related to the Champions League). The potential of these connections is not well exploited for news information, but when it is practiced, it reaches a major impact on Facebook.

\section{How to cite this text:}

Mercedes Herrero de la Fuente (2017): "New formulas for live television: the use of Facebook Live in Atresmedia", en Miguel Hernández Communication Journal, nº, pp. 521 to 563, Universidad Miguel Hernández, UMH (Elche-Alicante). Accessed 20 in: [paper link in mhjournal.org] 


\section{Introducción}

La revolución tecnológica de los últimos veinte años ha transformado profundamente el ámbito de los medios de comunicación y, en concreto, el de la televisión. El grupo Atresmedia ha sido pionero en incorporar las nuevas posibilidades de llegar a una audiencia potencial a través de Internet y especialmente de las redes sociales (Herrero, 2016).

Los informativos de Antena 3 son los primeros que utilizan en Marzo de 2015 la aplicación Periscope, gracias a la que se puede emitir audio y vídeo en directo desde un dispositivo móvil conectado a Internet. En febrero de 2017 se realiza el primer Periscope 360, poniendo en práctica una posibilidad ofrecida de forma selectiva por esta red social solo dos meses antes.

A finales de 2016 la estrategia de Social Media de Atresmedia introduce un nuevo elemento: Facebook Live. Se trata de una posibilidad de live streaming promovida por esta red social a principios del pasado año, que ha cobrado un gran protagonismo en pocos meses. Facebook Live (FBLive) es lanzado con una gran campaña publicitaria y acompañado de una inversión de cincuenta millones de dólares para incentivar la adopción de este servicio por parte de medios de comunicación, entre otros (Perlberg y Seetharaman, 2016).

Antena 3 introduce el live haciendo entrevistas a los concursantes de los talent show "Tu cara me suena" (TCMS) y "Tu cara no me suena todavía" (TCNMST) y también a los actores protagonistas de sus series de éxito, como "Mar de plástico" o "Amar es para siempre". El final de "Velvet", cuyo último capítulo se lleva a cabo en directo el pasado 22 de diciembre, es también objeto de numerosos FBLive en el perfil de la cadena. La respuesta de los usuarios de Facebook es contundente: algunos de estos vídeos han superado el millón de reproducciones. 
A partir de ese momento Antena 3 potencia el uso de FBLive frente al de Periscope y realiza este tipo de conexiones con cierta regularidad (sobre todo en la cuenta de la cadena). El live streaming pasa a ser un elemento clave para la interacción con los espectadores en TCMS y TCNMST, en los que se aprovechan las pausas publicitarias para entrevistar a los concursantes o los miembros del jurado, obteniendo un gran eco en Facebook.

\section{Objetivos}

Como hemos señalado, el uso del live streaming por parte de las grandes cadenas de televisión es una práctica reciente que está cambiando la manera de producir y consumir contenidos televisivos. Dentro de los numerosos aspectos que todavía están por investigar nos hemos centrado en un objetivo general, que podemos formular de esta manera: cómo y para qué se usa FBLive en los perfiles de Antena 3 y Antena 3 Noticias. Partiendo de esta idea, que es muy amplia, vamos concretando el foco de nuestro trabajo mediante unos objetivos específicos, buscando la comparación entre ambas cuentas:

- Analizar el contenido de estas emisiones y comparar los temas tratados.

- Examinar en profundidad los criterios formales, valorando si son equiparables a los usados habitualmente en las conexiones en directo en un sentido clásico.

- Valorar el impacto de los live en los dos perfiles de Facebook considerados.

- Averiguar si existe una estrategia claramente definida y delimitar los puntos fundamentales de la misma.

\section{Marco teórico}

En el objeto de nuestro estudio se cruzan diferentes líneas de investigación relacionadas con la audiencia social, el uso de live streaming en la difusión de contenidos televisivos, el periodismo móvil o las nuevas narrativas resultado de la convergencia de medios. Nos detenemos brevemente en cada uno de estos ámbitos que sirven de contexto a nuestra aportación. 


\subsection{De la Paleotelevisión a la Hipertelevisión y las narrativas transmedia}

El medio televisivo ha sufrido una gran transformación desde los años ochenta. La irrupción de canales privados en toda Europa multiplica la oferta de programas y da lugar a la primera fragmentación de las audiencias. Surge el fenómeno zapping y comienza una tendencia que no hará sino agrandarse: se difumina la frontera entre la información y el entretenemiento. El espectador queda sumido en un flujo de contenidos que le acompañan las 24 horas, concretando en la práctica el concepto teórico de planned flow apuntado por Raymond Williams (1975), que no es una mera sucesión de los diferentes programas emitidos, sino una secuencia planificada por la cadena que incluye publicidad y autopromociones.

Se asiste por tanto a un nuevo modelo que Umberto Eco denomina "Neotelevisión" (1986) (frente al modelo tradicional de "Paleotelevisión”). A las características anteriores Eco añade: "Habla de si misma y del contacto que está estableciendo con el público" (1986: 200). En efecto, mostrar la redacción de los informativos, los entresijos del plató, etc. es una manera de acercarse a la audiencia e intentar que siga asistiendo determinado programa.

En los noventa la televisión sigue transformándose y adaptándose a un contexto dominado por las posibilidades de interacción que brinda la tecnología digital. Distintos autores acuñan términos que intentan abarcar esta fase de cambio, desde la "Postelevisión" (Pisteicelli, 1998, Ramonet 2002) hasta la "Hipertelevisión" (Scolari, 2008). Nos centramos en este último concepto, no como una fase que sigue a la anterior, sino como una "particular configuración de la red sociotécnica" (Scolari, 2008:5). Se trata de una televisión dominada por el reality show y obsesionada por el directo (que va más allá de los informativos y se traslada a las series), cuyos contenidos se expanden a través de diferentes plataformas. Sus relatos se integran dentro de narraciones transmediáticas (Jenkins, 2003) y los propios espectadores 
colaboran en la distribución online de los contenidos, hasta convertirse incluso en creadores de los mismos. La Hipertelevisión cuenta con una audiencia fragmentada, ubicua y asíncrona, que intenta captar a un gran número de usuarios acostumbrados a la hipertextualidad y la interactividad. En este contexto de cambio los formatos antiguos conviven con los nuevos y también surgen contenidos híbridos.

Es inevitable al hablar de la televisión actual acudir a conceptos como "transmedia" o "crossmedia", cuya definición teórica no siempre se plasma con toda nitidez en los contenidos televisivos. En ambos casos nos refererimos a una historia contada a través de múltiples plataformas, pero tal vez el aspecto diferenciador de la narrativa transmedia sea el apuntado por Jenkins:

En la forma ideal de la narración transmedia, cada medio hace lo que mejor sabe hacer, de modo que una historia puede ser introducida en una película, expandida a través de televisión, novelas o cómics y su mundo podría ser explorado y experimentado a través del juego. Cada entrada de una franquicia debe tener autonomía suficiente para permitir el consumo independiente. Es decir, no es necesario haber visto la película para disfrutar del juego y viceversa, (2003, p.3).

Carmen Peñafiel concreta esta premisa:

no basta simplemente con el hecho de contar una historia o un relato informativo y fraccionar su contenido, sino que es necesaria una estrategia para que la audiencia se implique (...) y vaya pasando de un soporte a otro, de un enlace a otro, con el fin de que complete el recorrido que se le propone (...), (2016: 172) 
Jenkins (2003) se refiere también a la idea de crossmedia e incide en que en estas narrativas no se produce una expansión del relato, sino más bien una simple adaptación de la historia a las diversas plataformas. Este es, por tanto, el aspecto que distingue principalmente ambos planteamientos, el hecho de que en la experiencia crossmedia el contenido no se extiende de una forma pensada específicamente para cada ventana y las entradas en cada medio no siempre pueden consumirse de manera independiente.

La posibilidad de desarrollar un relato en múltiples plataformas mediante estrategias crossmedia o transmedia no pertenece solo a la ficción. También la información puede contarse a través de diversas ventanas que convergen, de modo que el contenido de una noticia se fracciona de forma intencionada. Tal como afirma Alberto Scolari, el periodismo siempre ha sido transmedia (2013), pero la tecnología digital ha permitido que se multipliquen estas posibilidades, presentadas en formatos muy atractivos y con gran número de vías de interacción.

Como ya hemos apuntado, entre los objetivos de este trabajo figura precisamente el de averiguar si existe una estrategia definida en el uso de FBLive por parte de Antena 3 y entre los aspectos de la misma trataremos la existencia (o no) de una narrativa transmedia.

\subsection{Audiencia social}

Partimos del concepto de "televisión social" formulado en los siguientes términos: "cuando canales alternativos como plataformas sociales sirven de canal conversacional en torno a lo que sucede en una programación”" (Castelló, 2013). En efecto FBLive es una herramienta perfecta para impulsar la interacción con la audiencia de un determinado programa durante su emisión (o no), o con el colectivo de "amigos" en esta red social, que reacciona ante los contenidos lanzados en directo. 
María José Arrojo (2013) señala cinco retos que deben plantearse las televisiones, todos ellos relacionados con la audiencia social. Recogemos aquí cuatro de ellos, por parecernos especialmente relevantes: aumentar la audiencia social, atraer a más espectadores mejorando la audiencia tradicional, obtener más datos sobre la opinión de la audiencia y aumentar el fenómeno fan sobre determinados contenidos.

En relación al primero, todas las grandes cadenas están presentes desde hace años en las principales redes sociales, especialmente Facebook. Las diferentes posibilidades de atraer al espectador han sido aprovechadas de forma inmediata (uno de los principales usos de Twitter es estar al tanto de las noticias) y por ello, a medida que surgen nuevas redes las existentes incorporan novedades. Sin duda la posibilidad de emitir contenidos en directo ha supuesto un cambio cualitativo que muchas televisiones han querido aprovechar. Ocurrió con Periscope en 2015 y ha vuelto a suceder con Facebook Live.

Existen evidencias que avalan el impacto que puede tener la evolución de la audiencia social sobre la tradicional. Basándose en datos de la consultora Nielsen, algunos autores afirman que "existe una correlación directa entre el aumento de comentarios sobre un programa y el crecimiento de espectadores tradicionales" (Saavedra y Rodríguez, 2016: 105). Sin duda la aparición de una noticia de impacto antes del informativo, puede llevar a que la misma persona que sigue esa última hora en FBLive quiera asistir también el informativo en televisión como audiencia tradicional.

El tercer reto formulado por Arrojo se refiere a conocer mejor a la propia audiencia. Hasta hace pocos años las mediciones aportaban sobre todo datos cuantitativos. La posibilidad de interactuar en las redes se convierte en una fuente de información realmente valiosa sobre nuestra audiencia y esos indicadores son de gran utilidad para los programadores, por no hablar de su valor para el mercado publicitario. Solo un apunte sobre lo anterior: como 
demuestra el estudio de Saavedra, Rodríguez y Barón (2015) en España los anunciantes no están aprovechando suficientemente este recurso y la compra de minutos de publicidad en los espacios de prime time no es acompañada de acciones para captar y fidelizar a la audiencia social.

Por último, sobre los fans, alternativas como Facebook Live resultan idóneas para alimentar este fenómeno. Los fans demandan curiosidades, primicias, chismorreos... El live streaming ofrece la emoción del directo y la posibilidad de hacer preguntas o regalar piropos a los ídolos.

Todo lo anterior gira en torno a distintas estrategias para conseguir el ansiado engagement, en un contexto en que el share se presenta más fragmentado. Del modelo tradicional de televisión, en el que el espectador consumía de forma bastante pasiva los distintos programas, cuyas audiencias eran ofrecidas a los anunciantes, hemos pasado a lo que Jenkins, Green y Ford denominan “engagement based paradigm" (2013, p. 124), en el que la relación con las audiencias se basa cada vez más en la interacción y los usuarios pueden participar de una forma más activa y directa en los contenidos de los distintos programas, haciendo que las historias se diseminen y de esta forma se incremente e intensifique ese engagement. Este objetivo encuentra su máxima expresión en el fenómeno fan, que además de aprovechar los canales de participación oficiales puede generar otros nuevos, de manera que "la producción oficial puede reutilizar los hallazgos narrativos del fandom”, (Tur Viñes y Rodríguez, 2014, p. 117).

La inclusión de contenidos televisivos en directo a través de una red social como Facebook parece una vía con un gran potencial para alcanzar esa meta, al añadirse la posibilidad de interaccionar en directo con determinados personajes o de hacer preguntas sobre determinada cobertura al propio periodista. 


\subsection{El live streaming en la difusión de contenidos televisivos}

El 82\% de los internautas de nuestro país consume vídeos habitualmente, según datos de comScore publicados a finales de 2016. Los vídeos representan casi la mitad del tráfico de Internet, al estar disponibles en gran parte de los sitios más visitados, como YouTube o Instagram. Las principales redes sociales se han adaptado a la publicación de vídeos y el último estadio en esta evolución ha sido, en algunas de ellas, la incorporación del live streaming.

Los medios han visto también la oportunidad de captar audiencias y han comenzado a experimentar con herramientas como FBLive. El directo es la forma más viva de hacer televisión y conjugar este formato con el potencial de las redes sociales puede ser una vía muy eficiente para estimular la interacción con un gran número de seguidores. "Se crea así una experiencia para el usuario que se siente parte activa del proceso comunicativo" (Mancebo, 2016: 345).

\subsection{El periodismo ciudadano y el fenómeno MoJ o}

Los cambios tecnológicos, en particular los relacionados con la telefonía móvil, han posibilitado que en determinadas situaciones cualquier ciudadano pueda convertirse en un informador por encontrarse en el momento y lugar adecuados. En los países donde no existe libertad de información este tipo de acciones puede adquirir especial relevancia, sobre todo para denunciar la violación de los derechos humanos y las libertades frente al resto del mundo (Espiritusanto, 2010).

La inmediatez y la autenticidad son los puntos fuertes del llamado periodismo ciudadano, que puede aportar material periodístico útil para confirmar o desmentir una información difundida por los medios (Bownan y Willis, 2003). En este contexto cambiante surge el fenómeno MoJo, término acuñado hace ya más de diez años en Estados Unidos para denominar al profesional de la comunicación que trabaja fuera de la redacción y que no utiliza los medios 
tradicionales para cubrir una noticia. El Mobil Journalism no afecta solo a los nuevos medios digitales: también "los tradicionales amplían y readaptan sus modelos de negocio a las redes de valor de los nativos digitales", (Campos, 2015: 446).

El periodista en la actualidad ha de elaborar contenidos tanto off como online, manejando también las redes sociales y sus continuas innovaciones, como el live streaming. Pero además, "en un mundo en el que estamos sobre informados, será el periodista el que tendrá que ordenar este caos informativo para los ciudadanos, jerarquizando, valorando y dándole sentido", (Andueza y Pérez, 2014: 599).

\section{Metodología}

\subsection{Datos relacionados con Facebook Live}

Los datos recopilados para esta investigación son básicamente las emisiones en directo realizadas para los perfiles de Facebook de Antena 3 y Antena 3 Noticias a lo largo de marzo de 20171. El núcleo de nuestro trabajo, por tanto, se sitúa en el estudio de estos dos casos concretos. Buscamos mediante el análisis comparativo detectar patrones comunes y también pautas diferenciadas (o no) en función de los contenidos.

Se estima que un mes es un tiempo suficiente para valorar qué estrategias está poniendo en práctica esta televisión y qué objetivos se persiguen. Entre las varias cuentas en Facebook de la cadena nos centramos en las dos mencionadas porque representan, por un lado, a Antena 3 en general y, por otro, a sus servicios informativos. Además están respaldadas por un amplio número de seguidores, con 1.734.005 para el perfil generalista y 1.112.507 para el perfil noticias (fecha consulta: 17 abril 2017).

Las emisiones en directo son objeto de una investigación cuantitativa, que contempla cuestiones relacionadas con el número de FBLive y su duración. 
Igualmente hemos contando con todos los datos sobre la proyección de estos live streaming en Facebook que maneja Atresmedia y que han sido puestos a nuestra disposición por parte de esta entidad para la realización de este artículo. De todos ellos hemos seleccionado los más representativos en función de nuestros objetivos, cuantificando los siguientes parámetros: visualizaciones (distinguimos entre impresiones y usuario único), reacciones ("me gusta", etc.), comentarios y compartidos.

Lo anterior se complementa con un estudio cualitativo ${ }^{2}$, que abarca de nuevo las características del propio vídeo, más su repercusión en términos de audiencia social. Los puntos fundamentales para este análisis son: tema, localización, estructura del contenido (pirámide invertida/espiral) ${ }^{3} \quad y$ determinados aspectos relacionados con la narrativa audiovisual, como son: personalización del periodista, tipo de plano (básicamente manejamos cuatro categorías: plano corto, plano medio, plano general, plano detalle), formato vertical/horizontal y movimientos (lo que en la terminología clásica se denominaría movimientos de cámara: plano fijo, paneo y zoom). Las pautas para el análisis del impacto en Facebook, desde un punto de vista cualitativo, se centran en los comentarios.

\subsection{Entrevistas en profundidad}

La investigación cualitativa va más allá de los datos recabados en Facebook. Utilizamos la entrevista en profundidad para conocer de primera mano el trabajo de los periodistas implicados en los FBLive emitidos en marzo y de los responsables de las redes sociales en Antena 3. Para ello elaboramos un cuestionario que es contestado por escrito entre finales de marzo y principios de abril por los siguientes profesionales:

- Antonio García, Coordinador de Social Media en Atresmedia.

- Antonio Baena, periodista de la sección de Sociedad de Antena 3 Noticias que habitualmente realiza FBLive para el perfil de los informativos. 
- Joana San Román, periodista parte del equipo de Social Media en Atresmedia.

\section{Análisis de los resultados}

5.1 Análisis del contenido. Temas tratados en los Facebook Live.

La siguiente tabla resume los contenidos de los live de Antena 3 Noticias en Facebook:

Tabla 1. Temas tratados en los FBLive de Antena 3 Noticias, marzo 2017

\begin{tabular}{|c|c|c|c|}
\hline \multicolumn{4}{|c|}{ FBLive Antena 3 Noticias } \\
\hline Fecha & Duración & Noticia/Tema & Localización \\
\hline 8 marzo & $02 \mathrm{~m} \mathrm{58s}$ & $\begin{array}{l}\text { Parón Atresmedia Día Mujer Trabajadora } \\
\text { SOCIEDAD }\end{array}$ & Exterior Atresmedia \\
\hline 9 marzo & $12 \mathrm{~m} 58 \mathrm{~s}$ & $\begin{array}{l}\text { Manu Sánchez y J. Antonio Paredero, pase a } \\
\text { cuartos Champions del Barcelona y el R. Madrid } \\
\text { DEPORTES (Fútbol) }\end{array}$ & Plató informativos \\
\hline 10 marzo & $17 \mathrm{~m} \mathrm{14s}$ & $\begin{array}{l}\text { Bacalao de vigilia } \\
\text { SOCIEDAD-CULTURA (Gastronomía) }\end{array}$ & $\begin{array}{l}\text { Cocina restaurante } \\
\text { "Urkiola Mendi" } \\
\text { (Madrid) }\end{array}$ \\
\hline 15 marzo & $09 \mathrm{~m} \mathrm{33s}$ & $\begin{array}{l}\text { Hombre atrincherado vivienda Orcasitas, 1. Llega } \\
\text { GEO } \\
\text { SOCIEDAD (Suceso) }\end{array}$ & Exterior vivienda \\
\hline 15 marzo & $13 \mathrm{~m} \mathrm{03s}$ & $\begin{array}{l}\text { Hombre atrincherado vivienda Orcasitas, } 2 . \\
\text { Amago desenlace } \\
\text { SOCIEDAD (Suceso) }\end{array}$ & Exterior vivienda \\
\hline 15 marzo & $08 \mathrm{~m} \mathrm{11s}$ & $\begin{array}{l}\text { Hombre atrincherado en vivienda de Orcasitas, } \\
\text { 3. Desenlace } \\
\text { SOCIEDAD (Suceso) }\end{array}$ & Exterior vivienda \\
\hline 17 marzo & $04 \mathrm{~h}$ & $\begin{array}{l}\text { Vota al equipo español que pasará a semifinales } \\
\text { Champions } \\
\text { DEPORTES (Fútbol) }\end{array}$ & Grafismo \\
\hline 22 marzo & $09 \mathrm{~m} \mathrm{29s}$ & $\begin{array}{l}\text { Calorías patata } \\
\text { SOCIEDAD-CULTURA (Gastronomía) }\end{array}$ & $\begin{array}{l}\text { Cocina restaurante } \\
\text { "Trigo" (Valladolid) }\end{array}$ \\
\hline
\end{tabular}


Como podemos observar se emiten 8 FBLive en el perfil Noticias y los temas se reparten como sigue: 2 de fútbol, 2 de gastronomía, 3 del mismo suceso, 1 de sociedad. En términos generales el contenido corresponde a la sección de Sociedad. De hecho, 5 de ellos están realizados por un periodista de esta sección, Antonio Baena. Por tanto, no hay una variedad de temas relacionados con las distintas secciones de la redacción.

Se observa una clara conexión con la actualidad en los lives relacionados con el suceso de Orcasitas, con los que se realiza una cobertura de la actualidad en el momento en que se produce y desde el mismo lugar de los hechos. La forma de exponer el contenido y los datos es similar al de las conexiones en directo habituales en los informativos (salvo por la duración, siendo el FBLive mucho más largo).

El perfil en Facebook de la cadena incluye en live streaming los temas siguientes:

Tabla 2. Temas tratados en los FBLive de Antena 3, marzo 2017 


\begin{tabular}{|c|c|c|c|}
\hline \multicolumn{4}{|c|}{ FBLive Antena 3} \\
\hline Fecha & $\underset{n}{\text { Duració }}$ & Noticia/Tema & Localización \\
\hline 3 marzo & $01 \mathrm{~m} \mathrm{41s}$ & $\begin{array}{l}\text { Final TCMS, entrevista A. Llàcer, jurado } \\
\text { programa } \\
\text { Promoción programa }\end{array}$ & Plató programa \\
\hline 3 marzo & $01 \mathrm{~m} \mathrm{43s}$ & $\begin{array}{l}\text { Final TCMS, entrevista concursantes L. } \\
\text { Gómez y C. Rodríguez } \\
\text { Promoción programa }\end{array}$ & Plató programa \\
\hline 3 marzo & $02 \mathrm{~m} \mathrm{50s}$ & $\begin{array}{l}\text { Final TCMS, entrevistas C. Latre, } \\
\text { concursantes B. Luengo y R. López. } \\
\text { También aparece presentador M. Fuentes } \\
\text { Promoción programa }\end{array}$ & Plató programa \\
\hline 6 marzo & $07 \mathrm{~m} \mathrm{48s}$ & $\begin{array}{l}\text { Entrevista concursante L. Gómez, tras } \\
\text { final TCMS } \\
\text { Promoción programa }\end{array}$ & Sala Atresmedia \\
\hline 7 marzo & $04 \mathrm{~h}$ & $\begin{array}{l}\text { Previo partido Napoli-R. Madrid. Votar } \\
\text { ganador } \\
\text { Promoción partido }\end{array}$ & Grafismo \\
\hline 8 marzo & $39 \mathrm{~m} \mathrm{41s}$ & $\begin{array}{l}\text { Presentación TCNMST. Presentador y } \\
\text { miembros jurado } \\
\text { Promoción programa }\end{array}$ & Plató programa \\
\hline $\begin{array}{l}10 \\
\text { marzo }\end{array}$ & $01 \mathrm{~m} \mathrm{51s}$ & $\begin{array}{l}\text { Estreno TCNMST. Entrevista miembros } \\
\text { jurado: A. Llàcer, etc. } \\
\text { Promoción programa }\end{array}$ & Plató programa \\
\hline $\begin{array}{l}10 \\
\text { marzo }\end{array}$ & $01 \mathrm{~m} \mathrm{19s}$ & $\begin{array}{l}\text { Estreno TCNMST. Entrevista } \\
\text { concursantes: J. Durán, A. Albiach, N. } \\
\text { Lozano y R. Calixta. } \\
\text { Promoción programa }\end{array}$ & Plató programa \\
\hline $\begin{array}{l}14 \\
\text { marzo }\end{array}$ & $04 \mathrm{~h}$ & $\begin{array}{l}\text { Previo Leicester City-Sevilla. Votar } \\
\text { ganador } \\
\text { Promoción partido }\end{array}$ & Grafismo \\
\hline $\begin{array}{l}15 \\
\text { marzo }\end{array}$ & $40 \mathrm{~m} \mathrm{29s}$ & $\begin{array}{l}\text { Entrevista C. Garrido, ganador primera } \\
\text { gala de TCNMST } \\
\text { Promoción programa }\end{array}$ & Sala Atresmedia \\
\hline $\begin{array}{l}15 \\
\text { marzo }\end{array}$ & $23 \mathrm{~m} \mathrm{09s}$ & $\begin{array}{l}\text { Entrevista F. Valenzuela, concursante } \\
\text { TCNMST } \\
\text { Promoción programa }\end{array}$ & Sala Atresmedia \\
\hline $\begin{array}{l}17 \\
\text { marzo }\end{array}$ & $01 \mathrm{~m} \mathrm{01s}$ & $\begin{array}{l}2^{a} \text { gala TCNMST. Entrevista miembros } \\
\text { jurado Chenoa, etc. } \\
\text { Promoción programa }\end{array}$ & Plató programa \\
\hline $\begin{array}{l}17 \\
\text { marzo }\end{array}$ & $02 \mathrm{~m} \mathrm{11s}$ & $\begin{array}{l}2^{a} \text { gala TCNMST. Entrevista } \\
\text { concursantes } \\
\text { Promoción programa }\end{array}$ & Plató programa \\
\hline $\begin{array}{l}17 \\
\text { marzo }\end{array}$ & $33 \mathrm{~s}$ & $\begin{array}{l}2^{\text {a }} \text { gala TCNMST. Presentador-Casting } 24 \\
\text { h. Promoción programa }\end{array}$ & Plató programa \\
\hline $\begin{array}{l}20 \\
\text { marzo }\end{array}$ & $14 \mathrm{~m} \mathrm{23s}$ & $\begin{array}{l}\text { Nueva temporada "Allí abajo". Entrevista } \\
\text { actor J. Plazaola } \\
\text { Promoción serie }\end{array}$ & Sala Atresmedia \\
\hline $\begin{array}{l}22 \\
\text { marzo }\end{array}$ & $36 \mathrm{~m} \mathrm{26s}$ & $\begin{array}{l}\text { Previo } 3^{\mathrm{a}} \text { gala TCNMST. Entrevista } \\
\text { concursante P. Aguilar }\end{array}$ & Sala Atresmedia \\
\hline
\end{tabular}




\begin{tabular}{|c|c|c|c|}
\hline & & Promoción programa & \\
\hline $\begin{array}{l}22 \\
\text { marzo }\end{array}$ & $38 \mathrm{~m} \mathrm{51s}$ & $\begin{array}{l}\text { Previo } 3^{\text {a }} \text { gala TCNMST. Entrevista } \\
\text { concursante Keunam } \\
\text { Promoción programa }\end{array}$ & Sala Atresmedia \\
\hline $\begin{array}{l}29 \\
\text { marzo }\end{array}$ & $24 \mathrm{~m} \mathrm{19s}$ & $\begin{array}{l}\text { Previo } 4^{\mathrm{a}} \text { gala TCNMST. Entrevista } \\
\text { concursante R. Ogalla } \\
\text { Promoción programa }\end{array}$ & Sala Atresmedia \\
\hline
\end{tabular}

El perfil de Antena 3 incluye 18 FBLive en marzo, la mayor parte de ellos (15) centrados en el programa "Tu cara me suena" o en su espacio heredero "Tu cara no me suena todavía". 2 live funcionan como previo al partido de la Champions que se emite esa misma noche y 1 anuncia la nueva temporada de la serie "Allí abajo". Por tanto, se trata de directos centrados en los programas de éxito de la cadena (todos los espacios mencionados son líder de audiencia en su franja).

Además se comparten 13 FBLive de otros perfiles de Atresmedia, en concreto: Antena 3 Cine (4), Celebrities (3), Antena 3 Noticias (2), El Tiempo (2), "Espejo Público" (1) y Ponle Freno (1). No vamos a incluir los live compartidos en nuestro análisis, pero nos gustaría mencionar que la temática sigue focalizada en los programas de la cadena.

\subsection{Análisis de los criterios formales: nuevos formatos televisivos}

Este punto de nuestro trabajo se centra en las pautas formales que predominan en los FBLive de las dos cuentas analizadas y toma como referencia el esquema clásico de los directos en los informativos de televisión. Se han definido unos parámetros recogidos en las siguientes tablas para articular un formato básico y a partir de ahí se ha procedido a una observación cualitativa y detallada, que exponemos después de cada tabla. 
Tabla 3. Criterios formales en los FBLive de Antena 3 Noticias, marzo 2017

\begin{tabular}{|c|c|c|c|c|c|}
\hline \multicolumn{6}{|c|}{ FBLive Antena 3 Noticias } \\
\hline FBLive & $\begin{array}{l}\text { Estructura } \\
\text { redacción }\end{array}$ & $\begin{array}{c}\text { Personaliza } \\
\text { periodista }\end{array}$ & $\begin{array}{c}\text { Tipo de } \\
\text { Plano }\end{array}$ & Formato & $\begin{array}{c}\text { Movimie } \\
\text { ntos }\end{array}$ \\
\hline $\begin{array}{l}\text { Mujer } \\
\text { trabajado } \\
\text { ra, parón } \\
\text { Atresme } \\
\text { dia }\end{array}$ & $\begin{array}{l}\text { Pirámide } \\
\text { invertida }\end{array}$ & Sí & $\begin{array}{l}\text { Plano } \\
\text { medio y } \\
\text { recursos }\end{array}$ & Vertical & $\begin{array}{l}\text { Sí. Paneos } \\
\text { recursos }\end{array}$ \\
\hline $\begin{array}{l}\text { Champio } \\
\text { ns } \\
\text { League. } \\
\text { Pase a } \\
\text { cuartos }\end{array}$ & Espiral & Sí & $\begin{array}{l}\text { Plano } \\
\text { americano } \\
\text { y plano } \\
\text { general }\end{array}$ & Horizontal & $\begin{array}{l}\text { No. Plano } \\
\text { fijo }\end{array}$ \\
\hline $\begin{array}{l}\text { Bacalao } \\
\text { de vigilia }\end{array}$ & $\begin{array}{l}\text { Pirámide } \\
\text { invertida }\end{array}$ & Sí & $\begin{array}{l}\text { Plano } \\
\text { americano } \\
\text { y plano } \\
\text { detalle. } \\
\text { Primer } \\
\text { plano } \\
\text { redactor }\end{array}$ & Vertical & $\begin{array}{l}\text { Paneos } \\
\text { recursos }\end{array}$ \\
\hline $\begin{array}{l}\text { Hombre } \\
\text { atrincher } \\
\text { ado } 1\end{array}$ & $\begin{array}{l}\text { Pirámide } \\
\text { invertida }\end{array}$ & No & $\begin{array}{l}\text { Plano } \\
\text { general y } \\
\text { recursos }\end{array}$ & Vertical & $\begin{array}{l}\text { Paneos } \\
\text { recursos. } \\
\text { Zoom }\end{array}$ \\
\hline $\begin{array}{l}\text { Hombre } \\
\text { atrincher } \\
\text { ado } 2\end{array}$ & $\begin{array}{l}\text { Pirámide } \\
\text { invertida }\end{array}$ & Sí, solo al final & $\begin{array}{l}\text { Plano } \\
\text { general y } \\
\text { recursos. } \\
\text { Primer } \\
\text { plano } \\
\text { redactor }\end{array}$ & Vertical & $\begin{array}{l}\text { Paneos } \\
\text { recursos }\end{array}$ \\
\hline $\begin{array}{l}\text { Hombre } \\
\text { atrincher } \\
\text { ado } 3\end{array}$ & $\begin{array}{l}\text { Pirámide } \\
\text { invertida }\end{array}$ & Sí, solo al final & $\begin{array}{l}\text { Plano } \\
\text { general y } \\
\text { recursos. } \\
\text { Primer } \\
\text { plano } \\
\text { redactor }\end{array}$ & Vertical & $\begin{array}{l}\text { Paneos } \\
\text { recursos }\end{array}$ \\
\hline $\begin{array}{l}\text { ¿Quién } \\
\text { pasará a } \\
\text { semifinal } \\
\text { es } \\
\text { Champio } \\
\text { ns? }\end{array}$ & --- & --- & --- & --- & --- \\
\hline $\begin{array}{l}\text { Calorías } \\
\text { patata }\end{array}$ & $\begin{array}{l}\text { Pirámide } \\
\text { invertida }\end{array}$ & Sí & $\begin{array}{l}\text { Plano } \\
\text { corto, } \\
\text { medio, } \\
\text { americano } \\
\text { y detalle. } \\
\text { Primer } \\
\text { plano } \\
\text { redactor }\end{array}$ & Vertical & $\begin{array}{l}\text { Paneos } \\
\text { recursos }\end{array}$ \\
\hline
\end{tabular}


La mayoría de estos directos nos recuerdan a los que vemos habitualmente en televisión, sea en un informativo clásico, sea en un programa tipo "España Directo", donde predominan este tipo de conexiones en vivo con movimiento del redactor y breves entrevistas a los protagonistas de la noticia. Dentro del primer tipo se encuadran los live sobre el suceso en Orcasitas y, dentro del segundo, los dedicados a temas gastronómicos y el del Día de la Mujer Trabajadora.

La duración se sitúa en torno a los 10-15 m. (con la única excepción del grafismo para votar relacionado con la Champions) y el criterio cuando se trata de un contenido en el que se espera un desenlace es, según nos explica el periodista Antonio Baena, realizar varias conexiones.

El contenido se ofrece por parte del redactor de forma siguiendo el esquema de pirámide invertida, comenzando por los datos más básicos, para luego ir ampliando. Aun así, debido a la larga duración de estas conexiones, el discurso es más repetitivo que en los directos que nos ofrecen habitualmente los informativos.

El informador está presente en los FBLive dedicados a gastronomía, pero aparece poco en los relativos al suceso (solo al final y no figura en el primero de ellos). En el ejemplo del Día de Mujer nos encontramos con una fórmula poco habitual en el formato live streaming: una periodista del departamento Social Media de Atresmedia se ocupa del móvil y locuta una parte del off de la conexión, mientras en el resto es una redactora de los informativos de televisión la que asume el protagonismo del directo y hace algunas preguntas a los presentes. Los live sobre fútbol se salen de estos parámetros. El primero por tratarse de un grafismo fijo donde no podemos aplicar este análisis. El segundo por ser una conversación en un plató entre dos periodistas deportivos, en la que una redactora de Social Media maneja el móvil y les transmite las preguntas formuladas en los comentarios de Facebook. 
En la entrevista realizada a Antonio Baena, este nos explica la conveniencia de que el redactor aparezca, si es posible al principio de la conexión. "Si el directo es desde un lugar de especial interés su presencia ha de ser más evidente, porque eso confiere mayor valor de cadena de televisión a ese FBLive".

Estas conexiones intentan mostrarnos algo del lugar de la noticia, por ello se hacen paneos con planos de recurso que sitúan al espectador. Hay más movimientos y variedad de planos en los live sobre temas gastronómicos, al caminar el periodista por una cocina. Aun así, no se trata de transmisiones muy pautadas. La mayoría de las televisiones tienen fijadas unas normas en cuanto al tipo de plano que se debe usar en los directos de los informativos, pero no se observa un protocolo cerrado en los FBLive. Es decir, que el redactor aparece en primer plano porque es la imagen posible cuando alguien se graba a si mismo con un móvil y los cambios de plano corto a medio o americano son bastante casuales, dependiendo de lo que se mueva el entrevistado.

Los live de Antena 3 Noticias suelen ir en formato vertical, aunque, como nos explica Antonio García, Coordinador de Social Media de Atresmedia, este criterio está cambiando: "Se utiliza en algunos casos, pero ya no es lo habitual. La ventaja que tiene es que al visualizarse en móvil hay más probabilidades de que ese usuario se mantenga viéndolo, porque ocupa más pantalla y tiene que hacer más scroll para pasarlo”.

La calidad del live es relativa, es decir, se mueven los planos, a veces se entrecorta el audio, se oye mucho el ambiente (como los comentarios de los profesionales de los medios a la puerta del inmueble de Orcasitas) y algunos terminan de forma abrupta. Pero al mismo tiempo estos directos transmiten inmediatez, espontaneidad y aportan a la audiencia una sensación de asistir a algo de lo que pasa detrás de la cámara (como las conversaciones de los participantes en el parón del 8 de marzo en Atresmedia). 
La tabla siguiente incluye los principales criterios formales en los directos desde Facebook para el perfil genérico de Antena 3:

Tabla 4.Criterios formales en los FBLive de Antena 3, marzo 2017

\begin{tabular}{|c|c|c|c|c|c|}
\hline \multicolumn{6}{|c|}{ FBLive Antena 3} \\
\hline FBLive & $\begin{array}{l}\text { Estructura } \\
\text { redacción }\end{array}$ & $\begin{array}{c}\text { Personaliza } \\
\text { periodista }\end{array}$ & $\begin{array}{c}\text { Tipo de } \\
\text { Plano }\end{array}$ & Formato & $\begin{array}{c}\text { Movimient } \\
\text { os }\end{array}$ \\
\hline $\begin{array}{l}\text { Final } \\
\text { TCMS. } \\
\text { Entrevista } \\
\text { miembro } \\
\text { jurado. } \\
\text { Pausa } \\
\text { publicidad }\end{array}$ & Espiral & No & $\begin{array}{l}\text { Plano } \\
\text { corto }\end{array}$ & Horizontal & $\begin{array}{l}\text { No. Plano } \\
\text { fijo }\end{array}$ \\
\hline $\begin{array}{l}\text { Final } \\
\text { TCMS. } \\
\text { Entrevista } \\
\text { concursante } \\
\text { s. Pausa } \\
\text { publicidad }\end{array}$ & Espiral & No & $\begin{array}{l}\text { Plano } \\
\text { corto }\end{array}$ & Horizontal & $\begin{array}{l}\text { No. Plano } \\
\text { fijo }\end{array}$ \\
\hline $\begin{array}{l}\text { Final } \\
\text { TCMS. } \\
\text { Entrevistas } \\
\text { C. Latre, } \\
\text { etc. Pausa } \\
\text { publicidad }\end{array}$ & Espiral & No & $\begin{array}{l}\text { Plano } \\
\text { medio y } \\
\text { plano } \\
\text { corto }\end{array}$ & Vertical & $\begin{array}{l}\text { Paneo, pero } \\
\text { muy poco }\end{array}$ \\
\hline $\begin{array}{l}\text { TCMS } \\
\text { entrevista } \\
\text { concursante } \\
\text { tras final }\end{array}$ & Espiral & No & $\begin{array}{l}\text { Plano } \\
\text { medio, } \\
\text { sentada }\end{array}$ & Horizontal & $\begin{array}{l}\text { No. Plano } \\
\text { fijo }\end{array}$ \\
\hline $\begin{array}{l}\text { Champions } \\
\text { League } \\
\text { previo } \\
\text { Napoli-R. } \\
\text { Madrid. }\end{array}$ & --- & --- & --- & --- & --- \\
\hline $\begin{array}{l}\text { TCNMST } \\
\text { presentació } \\
\text { n antes } \\
\text { estreno }\end{array}$ & Espiral & No & $\begin{array}{l}\text { Plano } \\
\text { general }\end{array}$ & Horizontal & $\begin{array}{ll}\text { No. Plano } \\
\text { fijo }\end{array}$ \\
\hline
\end{tabular}




\begin{tabular}{|c|c|c|c|c|c|}
\hline $\begin{array}{l}\text { TCNMST } \\
\text { estreno. }\end{array}$ & Espiral & No & $\begin{array}{l}\text { Plano } \\
\text { corto }\end{array}$ & Horizontal & $\begin{array}{l}\text { No. Plano } \\
\text { fijo }\end{array}$ \\
\hline $\begin{array}{l}\text { TCNMST } \\
\text { estreno. } \\
\text { Entrevista } \\
\text { concursant } \\
\text { es. Pausa } \\
\text { publicidad }\end{array}$ & Espiral & No & $\begin{array}{l}\text { Plano } \\
\text { general }\end{array}$ & Horizontal & $\begin{array}{l}\text { No. Plano } \\
\text { fijo }\end{array}$ \\
\hline $\begin{array}{l}\text { Champions } \\
\text { League } \\
\text { previo } \\
\text { Leicester } \\
\text { C.-Sevilla } \\
\end{array}$ & --- & --- & --- & --- & --- \\
\hline $\begin{array}{l}\text { TCNMST } \\
\text { entrevista } \\
\text { ganador } \\
\text { primera } \\
\text { gala } \\
\end{array}$ & Espiral & No & $\begin{array}{l}\text { Plano } \\
\text { medio, } \\
\text { sentado }\end{array}$ & Horizontal & $\begin{array}{l}\text { No. Plano } \\
\text { fijo }\end{array}$ \\
\hline $\begin{array}{l}\text { TCNMST } \\
\text { entrevista } \\
\text { concursant } \\
\text { e, previo } 2^{a} \\
\text { gala }\end{array}$ & Espiral & No & $\begin{array}{l}\text { Plano } \\
\text { medio, } \\
\text { sentado }\end{array}$ & Horizontal & $\begin{array}{l}\text { No. Plano } \\
\text { fijo }\end{array}$ \\
\hline $\begin{array}{l}\text { TCNMST } \\
2^{a} \text { gala. } \\
\text { Entrevista } \\
\text { miembros } \\
\text { jurado. } \\
\text { Pausa } \\
\text { publicidad }\end{array}$ & Espiral & No & $\begin{array}{l}\text { Plano } \\
\text { medio, } \\
\text { sentado. } \\
\text { Plano } \\
\text { american } \\
\text { o de pie }\end{array}$ & Vertical & $\begin{array}{l}\text { No. Plano } \\
\text { fijo }\end{array}$ \\
\hline $\begin{array}{l}\text { TCNMST } \\
2^{a} \text { gala. } \\
\text { Entrevista } \\
\text { concursant } \\
\text { es. Pausa } \\
\text { publicidad }\end{array}$ & Espiral & No & $\begin{array}{l}\text { Plano } \\
\text { medio y } \\
\text { plano } \\
\text { corto }\end{array}$ & Horizontal & $\begin{array}{l}\text { No. Plano } \\
\text { fijo }\end{array}$ \\
\hline $\begin{array}{l}\text { TCNMST } \\
2^{a} \text { gala. } \\
\text { Presentado } \\
\text { r- Casting } \\
24 \text { h. Pausa } \\
\text { publicidad }\end{array}$ & Espiral & No & $\begin{array}{l}\text { Plano } \\
\text { corto y } \\
\text { plano } \\
\text { medio }\end{array}$ & Horizontal & $\begin{array}{l}\text { No. Plano } \\
\text { fijo }\end{array}$ \\
\hline $\begin{array}{l}\text { "Allí } \\
\text { abajo" } \\
\text { nueva } \\
\text { temporada. } \\
\text { Entrevista }\end{array}$ & Espiral & No & $\begin{array}{l}\text { Plano } \\
\text { medio, } \\
\text { sentado }\end{array}$ & Horizontal & $\begin{array}{ll}\text { No. Plano } \\
\text { fijo }\end{array}$ \\
\hline
\end{tabular}




\begin{tabular}{|c|c|c|c|c|c|}
\hline actor & & & & & \\
\hline $\begin{array}{l}\text { TCNMST } \\
\text { previo } 3^{\mathrm{a}} \\
\text { gala. } \\
\text { Entrevista } \\
\text { concursant } \\
\text { e (P. } \\
\text { Aguilar) }\end{array}$ & Espiral & No & $\begin{array}{l}\text { Plano } \\
\text { medio, } \\
\text { sentado }\end{array}$ & Horizontal & $\begin{array}{ll}\text { No. Plano } \\
\text { fijo }\end{array}$ \\
\hline $\begin{array}{l}\text { TCNMST } \\
\text { previo } 3^{\mathrm{a}} \\
\text { gala. } \\
\text { Entrevista } \\
\text { concursant } \\
\text { e } \\
\text { (Keunam) }\end{array}$ & Espiral & No & $\begin{array}{l}\text { Plano } \\
\text { medio, } \\
\text { sentado }\end{array}$ & Horizontal & $\begin{array}{l}\text { No. Plano } \\
\text { fijo }\end{array}$ \\
\hline $\begin{array}{l}\text { TCNMST } \\
\text { previo } 4^{\mathrm{a}} \\
\text { gala. } \\
\text { Entrevista } \\
\text { concursant } \\
\text { e (R. } \\
\text { Ogalla) }\end{array}$ & Espiral & No & $\begin{array}{l}\text { Plano } \\
\text { medio, } \\
\text { sentado }\end{array}$ & Horizontal & $\begin{array}{l}\text { No. Plano } \\
\text { fijo }\end{array}$ \\
\hline
\end{tabular}

Nos encontramos con unos parámetros bastante homogéneos en estas conexiones, que se dividen en dos grupos: por un lado los FBLive de duración más breve (1-2 minutos) realizados en las pausas publicitarias de los programas TCMS y TCNMST, en el propio plató y, por otro, los más largos, que recogen una entrevista con un personaje relacionado con estos programas (y en un caso con la serie "Allí abajo"). En ambos detectamos unos patrones comunes:

- El contenido se organiza en espiral, de modo que se incide sobre un tema determinado y se repiten aspectos del mismo con algunas variaciones. Gran predominio de la entrevista.

- El redactor no aparece en plano. Uno o dos periodistas de Social Media graban con el móvil y hacen preguntas (que apenas se oyen), pero no figuran. 
- El formato es horizontal (con una sola excepción) y una de las razones para su uso nos la explica Antonio García: "En la mayoría de los casos se aprovechan trozos de ese FBLive, que es más extenso, para hacer pequeñas piezas en la web y si se hace en vertical dificulta mucho la tarea". Además, en el caso de las entrevistas, se busca la cercanía entre los entrevistados y los seguidores del live.

- No hay movimientos, el plano es fijo, pero en las dos categorías señaladas, este mismo criterio proporciona resultados distintos, como explicamos más adelante.

Los live del primer grupo muestran a los concursantes y el jurado, a veces también al presentador, y recogen el pulso del directo: cómo se está desarrollando la gala, con sus nervios y sus emociones. Aparecen varios de los protagonistas del momento, de modo que en el mismo plano salen distintos concursantes, o bien van y vienen, porque la conexión se realiza en los instantes en que están volviendo al plató al final de la publicidad. Se trata de directos muy vivos, llenos de declaraciones emotivas y espontáneas, donde los gritos del regidor para que todo el mundo ocupe sus puestos se escuchan de fondo. Muestran al espectador algo que no puede ver en la emisión de estos programas en televisión y le conectan con lo que ocurre detrás de las cámaras, permitiéndole además un feed back inmediato.

El segundo grupo de FBLive gira también en torno a los programas mencionados y se diferencia de los anteriores en la duración, entre 20 y 40 minutos. Se busca que el mayor número de personas se enganchen a la conexión. Se trata de entrevistas más preparadas, realizadas normalmente en las propias instalaciones de Atresmedia, en las que un concursante de TCMS o TCNMST cuenta a los seguidores de estos programas en Facebook cómo está siendo su experiencia. El entrevistado aparece sentado y con un micro de mano (este criterio nunca se seguiría en un directo convencional de televisión, donde se usaría micro de corbata) y los periodistas le hacen preguntas, cuyo audio es deficiente (ya que solo se cuenta con un micrófono). Según nos revela 
Antonio García, "se dan indicaciones al entrevistado para que cuando le hagamos una pregunta la repita al iniciar su respuesta". Los periodistas no aparecen en ningún momento en plano porque se busca que los seguidores del live tengan la impresión de "hablar" directamente con los entrevistados.

Cobran gran importancia los comentarios en Facebook, que son transmitidos al invitado por el periodista, y se busca un tono distendido. Por ello se invita al concursante a cantar o a llamar a otro participante en el concurso para que los seguidores de Facebook escuchen esa conversación e interactúen también con esa segunda persona. El carácter estático del plano fijo, que podría resultar en una narración aburrida, se compensa con los recursos mencionados.

La entrevista con Jon Plazaola, protagonista de "Allí abajo", sigue el esquema anterior. Los FBLive sobre la Champion, por los motivos ya indicados, obedecen a otros criterios y el directo de presentación de TCNMST también es diferente, ya que se trata de una serie de entrevistas a distintos miembros del jurado y al presentador de este espacio, que aparecen sentados en el plató del programa y hablan del mismo antes de su estreno.

\subsection{Impacto sobre la actividad en Facebook}

En esta tabla se resumen los principales datos de audiencia social para el Facebook de los informativos de Antena 3:

Tabla 5.Audiencia social de los FBLive de Antena 3 Noticias, marzo 2017

\begin{tabular}{|l|l|l|l|l|l|}
\hline \multicolumn{5}{|c|}{ FBLive Antena 3 Noticias } \\
\hline Facebook Live & $\begin{array}{l}\text { Visualizacio } \\
\text { nes } \\
\text { (impresiones } \\
\text { ) }\end{array}$ & $\begin{array}{l}\text { Visualizacio } \\
\text { nes (usuario } \\
\text { único) }\end{array}$ & $\begin{array}{l}\text { Reaccio } \\
\text { nes }\end{array}$ & $\begin{array}{l}\text { Comentari } \\
\text { os }\end{array}$ & $\begin{array}{l}\text { Compartid } \\
\text { os }\end{array}$ \\
\hline $\begin{array}{l}\text { Mujer } \\
\text { trabajadora, } \\
\text { parón } \\
\text { Atresmedia }\end{array}$ & 140.721 & 103.096 & 734 & 151 & 125 \\
\hline
\end{tabular}




\begin{tabular}{|l|c|c|c|c|c|}
\hline $\begin{array}{l}\text { Champions } \\
\text { League. Pase a } \\
\text { cuartos }\end{array}$ & 103.329 & 84.775 & 337 & 283 & 46 \\
\hline $\begin{array}{l}\text { Bacalao de } \\
\text { vigilia }\end{array}$ & 118.882 & 96.226 & 327 & 170 & 84 \\
\hline $\begin{array}{l}\text { Hombre } \\
\text { atrincherado 1 }\end{array}$ & $\mathbf{2 . 2 8 8 . 6 7 6}$ & $\mathbf{1 . 6 3 2 . 8 0 4}$ & 3.000 & 1.400 & 1.341 \\
\hline $\begin{array}{l}\text { Hombre } \\
\text { atrincherado 2 }\end{array}$ & 2.117 .807 & 1.541 .377 & 2.800 & 1.200 & 959 \\
\hline $\begin{array}{l}\text { Hombre } \\
\text { atrincherado 3 }\end{array}$ & 1.327 .853 & 950.491 & 2.900 & 642 & 845 \\
\hline $\begin{array}{l}\text { ¿uién pasará a } \\
\text { semifinales } \\
\text { Champions? }\end{array}$ & 2.057 .320 & 1.506 .451 & $\mathbf{1 1 . 0 0 0}$ & $\mathbf{2 . 3 0 0}$ & 362 \\
\hline \begin{tabular}{l} 
Calorías patata \\
\hline
\end{tabular} & 185.178 & 14.1703 & 751 & 193 & 133 \\
\hline
\end{tabular}

Las cifras de audiencia social indican un alto seguimiento de estos live streaming, destacando el elevado número de visualizaciones. La interacción también es elevada, sobre todo en las reacciones ("me gusta", etc.), seguida de los comentarios y los compartidos. Esta pauta es la habitual cuando se miden estas audiencias, ya que el hacer clic en "me gusta” es lo más rápido y lo que exige menos implicación. El seguidor se posiciona cuando hace un comentario o se lo piensa dos veces antes de compartir una publicación.

Nos gustaría destacar el éxito de los Facebook Live relativos al suceso de Orcasitas, que encabezan con gran diferencia sobre el resto el número de reproducciones (2.288.676 impresiones y 1.632.804 usuarios únicos) seguidos de cerca tan solo por el post sobre las semifinales de la Champions. En todo caso, hay que señalar que este último permaneció en directo durante aproximadamente 4 horas (desde antes de las 17.00 hasta comenzado el partido de esa noche) y al ser un grafismo no exige un tiempo de visualización. La primera conexión sobre la noticia del hombre atrincherado es también la más compartida (1.341). Lo anterior parece indicar que el seguimiento de la actualidad en directo es una fórmula a tener en cuenta por la cadena. 
Las conexiones sobre cocina, que obtienen resultados satisfactorios, son las que registran un seguimiento más bajo. Se trata de una modalidad que se inaugura en el mismo mes de marzo y que aspira a convertirse en una publicación regular un día a la semana (en abril ha continuado realizándose, normalmente los miércoles) bajo la denominación Facecook Live. El periodista Antonio Baena incluye estos live una vez emitidos en su propio blog de cocina "Lo que se cuece", ampliando la estrategia transmedia de este contenido.

Lamentablemente Facebook no facilita los datos del momento del directo, por lo que no podemos saber el seguimiento exacto de cada live en cuanto a visualización e interacciones en general.

En el plano cualitativo, los numerosos comentarios reflejan en la mayoría de los casos el entusiasmo de los seguidores, que reciben con mucha cordialidad las recetas o animan con fervor a su equipo de fútbol (el post sobre las semifinales de la Champions es el más comentado, con 2.300 entradas de seguidores). Debido a su elevado número no es posible en este trabajo realizar una reflexión detallada sobre los mismos, pero si podemos concluir que transmiten un feed back positivo.

En el suceso de Orcasitas los comentarios muestran una mayor complejidad, al introducirse temas como la violencia de género, lo que conduce a la controversia en algunos momentos. También proyectan cierta frivolidad respecto al asunto que se trata, con la inclusión de chistes sobre el barrio de Orcasitas o sobre la violencia machista. La repetición de comentarios como "Qué pasa", o "Dónde", demuestra la inmediatez que se busca en estos live, ya que el usuario podría encontrar respuesta a estas cuestiones simplemente pinchando el enlace a la web de Antena 3 Noticias que ofrece la conexión, o leyendo comentarios anteriores. Sin embargo formula tales preguntas a la espera de que otros seguidores le respondan sin apenas dilación. 
Sobre la interacción con los comentarios, donde se desarrolla de una forma más palpable es al final del post protagonizado por los periodistas deportivos, ya que la redactora de Social Media puede estar pendiente de las preguntas de los seguidores y transmitírselas a Sánchez y Paredero. En los demás casos la interacción es limitada, ya que es el mismo periodista el que está locutando la noticia, manejando el móvil y también leyendo los comentarios. Aun así, dicha interacción se produce, sobre todo, en los live realizados en los restaurantes, donde el redactor Antonio Baena es capaz de recoger varias cuestiones de la audiencia indicando incluso la identidad en Facebook de los que las formulan.

En cuanto al perfil de Antena 3, la audiencia social de los FBLive muestra también un seguimiento notable:

Tabla 6.Audiencia social de los FBLive de Antena 3, marzo 2017

\begin{tabular}{|l|c|c|c|c|c|}
\hline \multicolumn{1}{|c|}{ Facebook Live } & $\begin{array}{c}\text { Visualizaci } \\
\text { ones } \\
\text { impresion } \\
\text { es) }\end{array}$ & $\begin{array}{c}\text { Visualizaci } \\
\text { ones } \\
\text { (usuario } \\
\text { único) }\end{array}$ & $\begin{array}{c}\text { Reaccion } \\
\text { es }\end{array}$ & $\begin{array}{c}\text { Coment } \\
\text { arios }\end{array}$ & $\begin{array}{c}\text { Compar } \\
\text { tidos }\end{array}$ \\
\hline $\begin{array}{l}\text { Final TCMS. Entrevista miembro } \\
\text { jurado. Pausa publicidad }\end{array}$ & 373.638 & 266.249 & 1.600 & 824 & 85 \\
\hline $\begin{array}{l}\text { Final TCMS. Entrevista } \\
\text { concursantes. Pausa publicidad }\end{array}$ & 269.288 & 198.021 & 1.200 & 118 & 50 \\
\hline $\begin{array}{l}\text { Final TCMS. Entrevistas C. } \\
\text { Latre, etc. Pausa publicidad }\end{array}$ & 598.913 & 447.470 & 4.300 & $\mathbf{2 . 2 0 0}$ & 277 \\
\hline $\begin{array}{l}\text { TCMS entrevista concursante tras } \\
\text { final }\end{array}$ & 153.379 & 118.369 & 760 & 320 & 35 \\
\hline $\begin{array}{l}\text { Champions League previo } \\
\text { Napoli-R. Madrid. }\end{array}$ & $\mathbf{1 . 1 1 2 . 8 8 2}$ & $\mathbf{8 1 0 . 5 4 8}$ & $\mathbf{8 . 5 0 0}$ & 1.000 & $\mathbf{3 8 1}$ \\
\hline $\begin{array}{l}\text { TCNMST presentación antes del } \\
\text { estreno }\end{array}$ & 407.831 & 301.032 & 1.800 & 808 & 202 \\
\hline $\begin{array}{l}\text { TCNMST estreno. Entrevista } \\
\text { miembros del jurado. Pausa } \\
\text { publicidad }\end{array}$ & 349.110 & 250.489 & 2.200 & 760 & 98 \\
\hline $\begin{array}{l}\text { TCNMST estreno. Entrevista } \\
\text { concursantes. Pausa publicidad }\end{array}$ & 197.528 & 152.120 & 627 & 96 & 37 \\
\hline $\begin{array}{l}\text { Champions League previo } \\
\text { Leicester C.-Sevilla }\end{array}$ & 807.980 & 595.197 & 4.000 & 402 & 146 \\
\hline $\begin{array}{l}\text { TCNMST } \\
\text { entrevista ganador primera gala }\end{array}$ & 230.730 & 185.583 & 534 & 381 & 43 \\
\hline
\end{tabular}




\begin{tabular}{|l|c|c|c|c|c|}
\hline $\begin{array}{l}\text { TCNMST } \\
\text { entrevista concursante, previo 2a } \\
\text { gala }\end{array}$ & 220.127 & 179.445 & 439 & 274 & 35 \\
\hline $\begin{array}{l}\text { TCNMST 2a gala. Entrevista } \\
\text { miembros del jurado. Pausa } \\
\text { publicidad }\end{array}$ & 223.703 & 162.689 & 834 & 212 & 57 \\
\hline $\begin{array}{l}\text { TCNMST 2a gala. Entrevista } \\
\text { concursantes. Pausa publicidad }\end{array}$ & 154.882 & 112.873 & 590 & 152 & 54 \\
\hline $\begin{array}{l}\text { TCNMST 2a gala. Presentador- } \\
\text { Casting 24 h. Pausa publicidad }\end{array}$ & 93.866 & 69.793 & 201 & 12 & 26 \\
\hline $\begin{array}{l}\text { Serie “Alli abajo" nueva } \\
\text { temporada. Entrevista actor }\end{array}$ & 131.402 & 105.814 & 582 & 242 & 43 \\
\hline $\begin{array}{l}\text { TCNMST previo 3a gala. } \\
\text { Entrevista concursante (P. } \\
\text { Aguilar) }\end{array}$ & 317.118 & 247.351 & 789 & 826 & 75 \\
\hline $\begin{array}{l}\text { TCNMST previo 3a gala. } \\
\text { Entrevista concursante (Keunam) }\end{array}$ & 342.898 & 268.465 & 1.400 & 1.200 & 84 \\
\hline $\begin{array}{l}\text { TCNMST previo 4 gala. } \\
\text { Entrevista concursante (R. } \\
\text { Ogalla) }\end{array}$ & 184.255 & 147.726 & 529 & 237 & 34 \\
\hline
\end{tabular}

Destaca el éxito de las dos publicaciones relacionadas con la Champions. Son las más visualizadas. En concreto la del Napoli-R. Madrid obtiene 1.112.882 impresiones y 810.548 usuarios únicos y es también la que recaba más reacciones $(8.500)$. Aun así volvemos a precisar que se trata de posts diferentes al resto, por mantenerse en directo durante horas y no exigir la visualización real de un vídeo.

Dentro de los FBLive al uso, el más visto es la tercera conexión de la final de TCMS, que comienza con una intervención de Carlos Latre y pasa luego a breves entrevistas con algunos concursantes, entre ellos Rosa López. Recoge 598.913 impresiones y 447.470 usuarios únicos. También es el segundo vídeo con más "me gusta" (4.300) y el que produce mayor número de comentarios (2.200).

Sobre cuál de los dos formatos funciona mejor, los breves en las pausas de los programas TCMS y TCNMST, o los más largos con entrevistas a los protagonistas en los días previos al programa, se registra una ligera ventaja de los primeros, que tal vez es más reseñable porque obtienen en menos de dos 
minutos lo que las entrevistas más amplias captan en aproximadamente media hora. Los primeros se benefician de la gran audiencia de estos espacios y resultan atractivos por su naturalidad. Además del live arriba mencionado, el segundo más visto dentro de los ofrecidos durante la publicidad del programa es la segunda conexión de la final de TCMS (373.638 impresiones y 266.249 usuarios únicos), donde aparece el miembro del jurado y responsable del casting Ángel Llàcer. En relación a las entrevistas más largas, la que más visualizaciones obtiene es la del concursante Keunam (342.898 impresiones y 268.465 usuarios únicos).

Los live sobre fútbol son los más compartidos (381 y 146, respectivamente) junto al de Latre (277).

Sobre la cantidad de comentarios, sigue al vídeo de Latre el de la entrevista con el concursante Keunam, con 1.200.

Los comentarios de todos estas conexiones se caracterizan por el cariño que transmite la audiencia al programa y a sus concursantes (también al actor de la serie "Allí abajo" en su caso) a los que dedican todo tipo de halagos. Entre los que participan en estas interacciones figuran a veces otros concursantes, asicomo personas que se identifican como amigos, familiares, etc. Las entrevistas de larga duración recogen más comentarios (cuentan con más tiempo) y sobre todo consiguen una mayor interacción. En general se realizan por dos periodistas y uno de ellos, según nos explica la redactora de Social Media, Joana Sanromán, está pendiente de hacer llegar lo que expresa la audiencia al entrevistado. Sorprende la gran cantidad de fans que siguen estas conexiones desde diferentes lugares del mundo.

En los FBLive sobre fútbol los comentarios están totalmente centrados en animar a cada equipo (lo que a veces significa denostar a sus rivales) y en este caso, a pesar del gran número de entradas, no se produce una interacción tan 
completa, debido a que en estas publicaciones no interviene en directo un periodista.

\subsection{Estrategia de Antena 3 en el uso de Facebook Live.}

La inclusión del live en las dos cuentas de Facebook analizadas persigue la autopromoción de determinados programas de la cadena.

Este objetivo está muy claro en el perfil Antena 3 y se centra en TCMS y TCNMST. También en las retransmisiones de partidos de fútbol (en marzo coincidió con la Champions League) y en algunas series ("Allí abajo"). Para ello se intenta captar la audiencia en redes con acciones previas (la tarde antes del partido que se retransmite por la noche, dos días antes de la emisión en directo de TCMS o TCNMST, o el mismo día en que se estrena nueva temporada de una serie) y también simultáneas a los programas (es el caso de los dos talent shows).

Los propósitos no están tan definidos en cuanto a qué tipo de noticias/eventos cubrir en los FBLive de Antena 3 Noticias. Hemos destacado el éxito de las tres conexiones sobre un suceso en Madrid, es decir de una cobertura claramente informativa, que reproduciría las dinámicas de un directo para los informativos dentro de la emisión tradicional. Sin embargo, es la única publicación (aunque sea con tres post) de este tipo en todo el mes.

De las ocho publicaciones del perfil de los informativos, la mitad está directamente relacionada con una noticia de actualidad. Al suceso ya mencionado hay que sumar el parón del día de la Mujer Trabajadora. La otra mitad tiene que ver con el entretenimiento y aquí se encuadran las conexiones sobre fútbol y el llamado Facecook Live. Este comienza a introducirse y aspira a tener una periodicidad, pero solo dentro de unos meses podremos ver si se ha consolidado. 
En el perfil Noticias no hay acciones simultáneas al informativo y las acciones previas más claras repercuten en la Champions League. Puede que las conexiones sobre el suceso de Orcasitas inviten a ver el informativo (aunque en este caso el desenlace ya se conoce en el último live), aunque el redactor no se refiere en ningún momento a este espacio.

La organización del equipo humano y los medios técnicos también sigue unos protocolos más fijos para los FBLive de Antena 3. Lo habitual es que uno o dos periodistas de Social Media se encarguen de estas conexiones. En general son dos en las más largas, de forma que uno de ellos está pendiente de los comentarios en Facebook para promover la interacción con el entrevistado. Se realizan en el correspondiente plató o en una sala de Atresmedia. Los medios técnicos utilizados son: teléfono móvil ( Iphone alta gama), trípode, adaptador para micro de mano y micro de mano con su correspondiente cable, (a veces no se usa micrófono adicional).

En las conexiones para el perfil Noticias se sale al exterior y esto puede dificultar la transmisión. Los medios son mínimos, tan solo el móvil, y un único redactor se ocupa de todo. Pero no se trata de alguien que asuma solo este tipo de directos, ya que Antonio Baena, periodista que realiza los FBLive en marzo, trabaja para el informativo en su emisión tradicional y no dispone de una agenda fija en cuanto a los live que va a tener que desempeñar.

De una forma u otra, la finalidad de estas acciones es generar engagement y para ello existe una planificación con unas pautas más establecidas en los FBLive de Antena 3. Estos directos son un premio para el espectador, sobre todo para el de los programas de entretenimiento. Los contenidos son extra y dan la posibilidad de ver el contexto detrás de las cámaras.

Al propósito de atraer audiencia para los programas de la cadena se suma el de potenciar el tráfico en los webs de Antena 3 y Antena 3 Noticias. La mayoría de los FBLive proporcionan un enlace que remite a las mismas y además en 
los talent show se incluyen algunas referencias a la web. Por tanto, los live son parte de una estrategia global para optimizar el alcance del entorno digital de Antena 3. En los últimos doce meses esta cadena ha conseguido el liderazgo audiovisual en Internet ${ }^{4}$.

En cuanto al carácter transmedia o crossmedia de estas coberturas, los FBLive del perfil de la cadena forman parte de una estrategia más elaborada, donde la audiencia participa a través de sus comentarios y puede hacer preguntas en directo a determinados entrevistados, o pedir, por ejemplo, que canten determinada canción (como ocurre con los participantes de TCNMST). Estos live aportan un contenido distinto al de la emisión televisiva y pensado de forma específica para esa plataforma. Lo mismo ocurre con las conexiones en las pausas publicitarias, en las que los streaming muestran lo que ocurre en el plató durante esos minutos, algo a lo que el espectador televisivo no tiene acceso. Podría decirse, por tanto, que la estrategia está orientada a una experiencia trasnmedia.

En la cuenta de Antena 3 Noticias los recursos son más limitados, ya que un único redactor realiza el directo y está pendiente de los comentarios durante el live. Esto reduce las posibilidades de interacción, que se producen, pero en menor medida. Por otro lado, su contenido es en la mayoría de los casos el mismo que ofrecería un directo dentro de un informativo al uso. Con algunas variaciones, ya que, en el suceso de Orcasitas, se muestra el contexto de la cobertura periodística y se oyen los comentarios de los cámaras y redactores que están cubriendo esta noticia, a lo largo de un live mucho más largo que un directo al uso. Lo mismo ocurre en el parón por el Día de la Mujer Trabajadora, donde también se escuchan las conversaciones de los participantes en el mismo y, de nuevo, por su duración, se incluyen imágenes de recursos que no son las estándar en una emisión clásica. Aun así, esta estrategia, como venimos diciendo en esta artículo, cuenta con menos elaboración, es más improvisada, y por ello se sitúa dentro de un contexto más cercano a la narración crossmedia. 
El uso de Facebook para conexiones en directo supone una caída en el número de streaming a través de Periscope. En marzo solo se realizan dos con una duración en torno a los cinco minutos y están dedicados al Mobile World Congress de Barcelona, celebrado a principios de ese mes. El número de reproducciones es de 5.142 en la primera y 5.377 en la segunda, una cifra bastante por debajo de la recogida por los FBLive (consultado el 5 de abril de 2017). Sin cuestionar el éxito de Periscope, es evidente que los FBLive pueden proporcionar un seguimiento muy superior por tratarse de la red social más usada en España, donde ya hay mucho tráfico por otros contenidos fuera de los live. A Periscope solo se entra para ver una conexión, normalmente avisados por una notificación, pero no acumulamos esta audiencia a otras que transitan por esa aplicación por otros motivos. FBLive también nos avisa en el momento del directo, pero podemos acceder a esta red social por otras razones y eso proporciona un mayor eco y hace que estos post perduren más en el tiempo. Antonio García define Periscope como "una red más efímera, donde no es tan fácil localizar lo que se publicó anteriormente".

\section{Conclusiones}

1. Las televisiones usan desde hace años las redes sociales como un instrumento más para captar audiencias y eso incluye adoptar todas las posibilidades que estas les ofrecen, incluyendo en el caso de Antena 3 el FBLive.

2. Los dos perfiles de Facebook analizados para esta cadena usan estos live streaming para promocionar determinados programas. Esta meta está clara en la cuenta de Antena 3, centrada en los talent shows, el fútbol y las series. El impulso de los informativos no está tan bien definido por parte del perfil Noticias, que además de ofrecer temas de actualidad incluye también fútbol o gastronomía.

No hay forma de cuantificar con cifras el impacto del FBLive sobre la audiencia tradicional de estos espacios, pero a juzgar por los resultados 
registrados en marzo, cuando TCMS, TCNMST y la serie "Allí abajo" son líderes en su franja y obtienen en dos ocasiones el minuto de oro de la jornada ${ }^{5}$, parece que el objetivo de mejorar el engagement se ha cumplido en cuanto al entretenimiento se refiere.

3. Además el eco de los live en las cifras de tráfico dentro de Facebook es notable, alcanzando con algunas publicaciones más de 2 millones de reproducciones. Los datos recabados y expuestos anteriormente revelan igualmente una interacción intensa a través de reacciones, comentarios y compartidos. Sin desmerecer el éxito de la cuenta de Antena 3 en este sentido, hay que señalar que es una de las conexiones sobre un suceso informativo publicada en el perfil Noticias la que recoge más visualizaciones en el mes de marzo. Dicho dato no debería pasar desapercibido y tal vez sea este tipo de coberturas inmediatas desde el lugar de los hechos lo que puede aportar un plus a los FBLive en Antena 3 Noticias.

4. En estos directos los criterios formales son secundarios y se da prioridad a la inmediatez y la frescura del momento frente a la factura audiovisual. Las pautas en cuanto a tipo de plano, movimientos, formato vertical/horizontal o presencia del periodista presentan una mayor convergencia en el perfil de Antena 3, sobre todo en las entrevistas de larga duración realizadas en las instalaciones de la propia cadena (que son estáticas, en plano medio, formato horizontal y sin presencia del periodista). Los live de la cuenta Noticias desarrollan un lenguaje audiovisual más dinámico y en general reproducen el esquema de un directo tradicional, donde según el tema o la duración hay más o menos margen para las entrevistas breves y el cambio de plano, con personalizaciones del periodista y predominio del formato vertical.

5. Este tipo de acciones exigen la adaptación del periodista, que ha de manejar nuevas herramientas de trabajo y modelar su lenguaje en relación a las posibilidades que proporciona FBLive. Las conexiones de la cuenta Antena 3 Noticias son asumidas enteramente por un único redactor, que maneja el 
móvil, se ocupa de narrar el correspondiente contenido, hace las entrevistas (en su caso), personaliza y da eco a los comentarios de los que le siguen en directo. Todo ello con unos recursos materiales mínimos (un teléfono móvil). Además los profesionales que realizan estos live trabajan para la emisión tradicional de Antena 3, de modo que compaginan estas intervenciones en Facebook con su día a día en la redacción de informativos.

En el perfil de Antena 3 es el equipo de Social Media quien lleva a cabo estos directos (una o dos personas) y durante los mismos hacen preguntas al entrevistado y le transmiten los comentarios que aparecen en Facebook. No personalizan, no asumen la narración de un evento o noticia y su función es básicamente que el espectador sea testigo de lo que se quiere mostrar, bien lo que sucede en el plató de un programa, bien un encuentro más pausado para charlar con un personaje que se estima de interés para los seguidores de determinado espacio. Se puede decir que lo que persiguen es un contacto estrecho entre la audiencia y aquello que se exhibe en el live, para que el espectador tenga la sensación de hablar con su ídolo o encontrarse en el plató durante la gala de un talent show.

6. FBLive es un recurso eficiente dentro de una narrativa que se acerca a lo transmedia, donde las audiencias siguen sus programas favoritos a través de distintas pantallas y están ávidas de contenidos extra, no ofrecidos en la emisión tradicional. Este tipo de directos aporta una experiencia diferente, mostrando un contexto que no suele aparecer en televisión y dando la posibilidad a los usuarios de Facebook de interactuar con personajes populares. Los contenidos de determinados espacios se prolongan en el tiempo y se intensifican, con conexiones en los días previos, durante la propia emisión y también en momentos posteriores. Detectamos una estrategia con unos protocolos bastante pautados en la cuenta de Antena 3, como hemos señalado en puntos anteriores. 
En el perfil Noticias los live no siguen un esquema tan claro, ni están directamente asociados a un programa determinado, (salvo los relacionados con el fútbol, que se ofrecen horas antes de los partidos). Presentan un carácter más experimental, recogen la actualidad del día, pero no solo, y tal vez precisan de una mayor definición en lo que a temática se refiere, además de una periodicidad, como parece intentarse con el denominado Facecook Live. Estos streaming apenas aportan contenidos extra y las posibilidades de interacción de la audiencia se ven disminuidas por las limitaciones de personal, ya que el mismo redactor que personaliza durante el FBLive se ocupa también de dar eco a los comentarios de la audiencia. Aunque su duración ronda los diez minutos, son directos bastante semejantes a los ofrecidos en la emisión tradicional, por lo que se trata de una adaptación del contenido, más que de una narración planteada de forma específica para esa plataforma. Por todo lo anterior, podemos decir que los FBlive de Antena 3 Noticias se sitúan dentro de una estrategia crossmedia.

\section{Bibliografía}

Andueza, M.B. y Pérez, R. (2014). El móvil como herramienta para el perfil del nuevo periodista. Historia y Comunicación Social, vol. 19, $\mathrm{n}^{\mathrm{o}} \mathrm{Esp}$, enero, pp. 591-602. Recuperado de https://revistas.ucm.es/index.php/HICS/article/view/44987/42358

(Consultado el 2 de diciembre de 2016).

Arrojo, M. J. (2013). La televisión social. Nuevas oportunidades y nuevos retos para el sector audiovisual. I Congreso Internacional de Comunicación y Sociedad Digital. 17, 18 y 19 de abril, Universidad Internacional de La Rioja.

Bowman, S. y Willis, C. (2003). WeMedia. How audiences are shaping the future of news and information, Media Center at the American Press Institute. Recuperado de http://www.hypergene.net/wemedia/download/we_media.pdf (Consultado el 11 de enero de 2017). 
Campos, F. (2015). Adaptación de los medios tradicionales a la innovación de los metamedios. El profesional de la información, vol. 24, n 4, pp. 441-450. Recuperado de http://www.elprofesionaldelainformacion.com/contenidos/2015/jul/11.pdf (Consultado el 2 de febrero de 2017).

Castelló, A. (2013). El uso de hashtags en Twitter por parte de los programas de televisión españoles. I Congreso Internacional de Comunicación y Sociedad Digital. 17, 18 y 19 de abril, Universidad Internacional de La Rioja.

Eco, U. (1986). La estrategia de la ilusión. Barcelona: Lumen.

Espiritusanto, O. (2010). Periodismo ciudadano. El fenómeno MoJo. Telos, nº 83 (Dossier. Una sociedad en movilidad: nuevas fronteras), pp. 100-103. Recuperado de: https: / / telos.fundaciontelefonica.com/seccion=1268\&idioma=es_ES\&id=20 10051309470001\&activo=6.do (Consultado el 14 de enero de 2017).

Herrero, M. (2016). Análisis de la audiencia social en la programación informativa de prime time. El caso de Atresmedia. En M. Saavedra y L. Rodríguez (Ed.), Audiencia social. Estrategias de comunicación para medios y marcas, pp. 73-88. Madrid: Síntesis.

Jenkins H., Green J. y Ford S. (2013). Spreadable Media. Creating value and meaning in a networked culture. Nueva York: New York University Press.

Jenkins, H. (2003). Transmedia Storytelling. MIT Technology Review, 15 enero. Recuperado de: https://www.technologyreview.com/s/401760/transmedia-storytelling (Consultado el 4 de marzo de 2017). 
Mancebo, M. (2016). Innovación en formatos audiovisuales. El uso de herramientas de live streaming en Antena 3 y Univision. Miguel Hernández Communication Journal, $\mathrm{n}^{\circ}$, pp. 325-349. Recuperado de file:///C:/Datos/152-620-1-PB.pdf (Consultado el 14 de noviembre de 2016).

Peñafiel, C. (2016). Reinvención del periodismo en el ecosistema digital y narrativas transmedia. adComunica. Revista Científica de Estrategias, Tendencias e Innovación en Comunicación, no 12, pp. 163-182. Recuperado de

http://www.adcomunicarevista.com/ojs/index.php/adcomunica/article/view /341/301 (Consultado el 4 enero de 2017).

Perlberg, S. y Seetharaman, D. (2016). "Facebook Signs Deals With Media Companies, Celebrities for Facebook Live", Wall Street Journal, 22 junio. Recuperado de https://www.wsj.com/articles/facebook-signs-deals-withmedia-companies-celebrities-for-facebook-live-1466533472 (Consultado el 24 enero de 2017).

Piscitelli, A. (1998). Post-televisión. Ecología de los medios en la era de Internet. Buenos Aires: Paidós.

Ramonet, I. (ed.) (2002). La post-televisión: Multimedia, Internet y globalización económica. Barcelona: Icaria.

Saavedra, M. y Rodríguez, L. (2016). Audiencia social. Una oportunidad para el medio televisivo y para la estrategia publicitaria. Telos, n ${ }^{\circ} 103$, pp. 102-110. Recuperado de https: / / telos.fundaciontelefonica.com/seccion=1268\&idioma $=$ es_ES\&id $=20$ 16030914390001\&activo=6.do (Consultado el 4 de enero de 2017). 
Saavedra, M., Rodríguez, L. y Barón, G. (2015). Audiencia social en España: Estrategias de éxito en la televisión nacional. Icono14. Revista científica de Comunicación y Tecnologías emergentes, vol. 13, n 2, pp. 214-237. Recuperado de http://www.icono14.net/ojs/index.php/icono14/article/view/822/534 (Consultado el 4 de enero de 2017).

Scolari, C. A. (2013). Narrativas transmedia. Cuando todos los medios cuentan. Bilbao: Deusto.

Scolari, C. A. (2008). Hacia la hipertelevisión. Los primeros síntomas de una nueva configuración del dispositivo televisivo. Diálogos de la comunicación, $\mathrm{n}^{\circ}$ 77, pp. 1-9. Recuperado de http://dialogosfelafacs.net/wpcontent/uploads/2015/77/77-revista-dialogos-hacia-la-hipertelevision.pdf (Consultado el 30 de julio de 2017).

Tur Viñes V. y Rodríguez, R. (2014). Transmedialidad, Series de Ficción y Redes Sociales. El Caso de Pulseras Rojas en el Grupo Oficial de Facebook (Antena 3. España). Cuadernos.info, no 34, pp. 115-131. Recuperado de: http://cuadernos.info/index.php/CDI/article/view/cdi.34.549/pdf. (Consultado el 29 de julio de 2017).

Williams, R. (1974). Televisión: Technology and Cultural Form. Londres: Fontana.

Global Digital Future in Focus (2016). comScore Report. Recuperado de http://www.comscore.com/Insights/Presentations-andWhitepapers/2016/2016-Global-Digital-Future-in-Focus (Consultado el 14 de enero de 2017). (Consultado el 8 de enero de 2017). 


\section{Enlaces de los FBLive mencionados en este trabajo:}

Perfil Antena 3 Noticias

Parón Día Mujer

https://www.facebook.com/antena3noticias/videos/10155244321494427/

Champions League, Sánchez y Paredero

https://www.facebook.com/antena3noticias/videos/10155250562894427/

Bacalao vigilia

https://www.facebook.com/antena3noticias/videos/10155253092719427/

Horcasitas conexión 1

https://www.facebook.com/antena3noticias/videos/10155271298849427/

Horcasitas conexión 2

https://www.facebook.com/antena3noticias/videos/10155271348944427/

Horcasitas conexión 3

https://www.facebook.com/antena3noticias/videos/10155271391029427/

Cartón Champions League

https://www.facebook.com/antena3noticias/videos/10155277269759427/

Calorías patata

https://www.facebook.com/antena3noticias/videos/10155292831514427/

Perfil Antena 3

Final TCMS, entrevista C. Latre, concursantes, etc.

https://www.facebook.com/antena3/videos/10154506239101298/

Final TCMS, entrevista concursantes L. Gómez y C. Rodríguez

https://www.facebook.com/antena3/videos/10154506295316298/

Final TCMS, entrevista jurado A. Llàcer

https://www.facebook.com/antena3/videos/10154506367061298/

TCMS, entrevista concursante L. Gómez

https://www.facebook.com/antena3/videos/10154513772251298/

Champions League, previo Napoli R. Madrid 
https://www.facebook.com/antena3/videos/10154517513046298/ Presentación TCNMST

https://www.facebook.com/antena3/videos/10154520414211298/ Estreno TCNMST, entrevista concursantes https://www.facebook.com/antena3/videos/10154529809266298/ Estreno TCNMST, entrevista miembros jurado https://www.facebook.com/antena3/videos/10154529864141298/ Champions League, previo Leicester City-Sevilla https://www.facebook.com/antena3/videos/10154541355026298/ TCNMST, entrevista concursante C. Garrido https://www.facebook.com/antena3/videos/10154543538386298/ TCNMST, entrevista concursante F. Valenzuela https://www.facebook.com/antena3/videos/10154544040106298/ TCNMST, segunda gala, entrevista miembros jurado https://www.facebook.com/antena3/videos/10154550300451298/ TCNMST, presentador-casting $24 \mathrm{~h}$. https://www.facebook.com/antena3/videos/10154550366276298/ TCNMST, segunda gala, entrevista concursantes. https://www.facebook.com/antena3/videos/10154550300451298/ "Allí abajo", entrevista J. Plazaola https://www.facebook.com/antena3/videos/10154557036996298/ TCNMST, entrevista concursante Keunam https://www.facebook.com/antena3/videos/10154563082771298/ TCNMST, entrevista concursante P. Aguilar https://www.facebook.com/antena3/videos/10154563338001298/ TCNMST, entrevista concursante R. Ogalla https://www.facebook.com/antena3/videos/10154582154971298/ 


\section{Notas}

1 Los enlaces de todos los live objeto de nuestra investigación se incluyen al final de este artículo.

${ }^{2}$ El tratamiento de estos parámetros es predominantemente cualitativo, ya que lo que nos interesa es analizar el carácter expreviso de la personalización/no personalización, los tipos de plano, el formato y los movimientos de cámara. Es cierto que el predominio de unos criterios sobre otros nos lleva a saber cuáles son más habituales, pero su cuantificación no es lo prioritario en nuestro estudio.

3 Frente a la clásica pirámide invertida como estructura que expone los principales aspectos de una información periodística, yendo de los datos fundamentales a los secundarios y respondiendo a las famosas seis "W", los streaming pueden presentar una organización del contenido menos secuencial y que incluye repeticiones. Esto se debe a que no todos los seguidores se conectan desde el inicio por lo que, sin perder de vista el esquema principiomedio-fin, se recurre a recordatorios y se abunda en detalles.

${ }^{4}$ Datos publicados en la web de Antena 3, (consultada el 20 de abril de 2017). http://www.antena3.com/noticias/tecnologia/segundo-mejor-dato-historicoweb-antena-millones-usuarios-

unicos_2017042058f8d4000cf2461b6dded2b4.html

5 Datos consultados en las siguientes webs (fecha de consulta 19 abril 2017): http://www.formulatv.com/audiencias/2017-03-03/

http://www.formulatv.com/audiencias/2017-03-10/

http://www.formulatv.com/audiencias/2017-03-17/

http://www.formulatv.com/audiencias/2017-03-24/

http://www.formulatv.com/audiencias/2017-03-20/

http://www.formulatv.com/audiencias/2017-03-27/ 


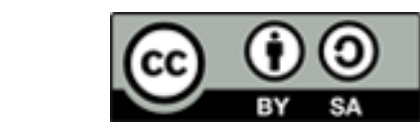

Licencia Creative Commons

Miguel Hernández Communication Journal

mhjournal.org

\section{Cómo citar este texto:}

Mercedes Herrero de la Fuente (2017): "Nuevas fórmulas para la televisión en directo: el uso de Facebook Live en Atresmedia", en Miguel Hernández Communication Journal, nº pp. 521 a 563. Universidad Miguel Hernández, UMH (Elche-Alicante). Recuperado el _ de de 20_ de: @ink del artículo en mhjournal.org] 